\title{
Os conflitos das políticas da água e do esgotamento sanitário: que universalização buscamos?
}

\author{
MARIANA GUTIERRES ARTEIRO DA PAZ, ${ }^{I}$ \\ ANA PAULA FRACALANZA, "I ESTELA MACEDO ALVES, ${ }^{I I I}$ \\ e FLÁVIO JOSÉ ROCHA DA SILVA ${ }^{I V}$
}

\section{Introdução}

A

ÁGUA é um bem comum, um "recurso compartilhado por um grupo de pessoas" (Hess; Ostrom, 2007, p.4) e, apesar do capitalismo dominante no Ocidente, faz parte de um regime de utilização não capitalista (Dardot; Laval, 2014), por ser fonte de vida. É fundamental para atividades humanas diárias, como hidrovias, indústria ou lazer. Mas o consumo humano, por seu valor vital, é prioridade em relação aos demais usos, em casos de escassez. O direito humano à água é assegurado por resolução da Organização das Nações Unidas (ONU), desde julho de 2010, devendo ser observado pelos países signatários. No Brasil, esse direito é assegurado pela Política Nacional de Recursos Hídricos (PNRH) e "em situações de escassez, o uso prioritário dos recursos hídricos é o consumo humano e a dessedentação de animais" (Lei Federal n.9.433/1997).

Relatórios da ONU e organismos associados apontam que, no Brasil, ocorreram avanços significativos no saneamento no período de 2000 a 2017; no entanto, a qualidade dos serviços de abastecimento de água e de esgotamento sanitário ainda são deficientes e desiguais (Opas Brasil, 2019). Cerca de dois bilhões de pessoas têm acesso deficiente; nas zonas rurais, sete em cada dez habitantes não têm saneamento; os países em desenvolvimento abrigam um terço das pessoas afetadas e crianças de comunidades pobres e rurais correm o maior risco de serem desprovidas dos serviços de água e esgoto e à higiene adequada (Opas Brasil, 2019). Os movimentos para suprir os déficits no acesso aos serviços de água e saneamento são prioritários e urgentes e precisam considerar as iniquidades, para que se garanta a distribuição de forma segura (Murtha et al., 2015; Fracalanza et al., 2013; Britto, 2010; Maricato, 2003). Os conflitos associados à água nas cidades estão ligados às escolhas sobre onde investir em infraestrutura e se a água e seus serviços devem ser tratados como mercadorias ou bens comuns (Alves, 2018). 
Tendo em vista a importância da equidade na obtenção de recursos naturais e da justiça ambiental no acesso aos serviços de saneamento - especificamente abastecimento de água e esgotamento sanitário - para diminuição dos quadros de vulnerabilidade socioambiental das populações humanas, pergunta-se: por que, embora a universalização seja objetivo do planejamento do saneamento básico, os investimentos equitativos ainda são tímidos?

Em um mundo em constante transformação, a noção de desenvolvimento deixou de ser sinônima de crescimento econômico e incorporou questões sociais e variáveis ambientais. Nesse sentido, o desenvolvimento sustentável apareceu como um caminho que propunha limites ao crescimento desordenado. Atualmente (2020), na pandemia da Covid-19 que presenciamos, observa-se que continuam as dificuldades relacionadas aos serviços de abastecimento de água, o que pode dificultar ações de combate à propagação do vírus para populações vulneráveis que habitam regiões metropolitanas, já que as relações socioeconômicas e de contágio se dão além das fronteiras territoriais politicamente definidas.

Schmidt et al. (2019) observam que, em contextos de degradação global, um desafio importante é romper com o conhecimento compartimentado que reforça as noções de ambiente e sustentabilidade, recolocando os seres humanos no centro das preocupações da ciência. Assim, este artigo tem como objetivo discutir as relações estabelecidas entre a gestão da água e do esgotamento sanitário em razão das dimensões sociais e ambientais, nas agendas políticas do Brasil e de um comitê de bacia paulista. Para esse debate, o texto divide-se em: i) panorama global do acesso à água potável e ao esgotamento sanitário; ii) contextualização socioambiental do saneamento básico no Brasil; iii) o acesso à água e ao saneamento sanitário como direito humano; e iv) que universalização queremos? (desdobramento da definição de universalização dos serviços de saneamento básico em três esferas de gestão da água, no Brasil).

\section{Panorama global do acesso a água potável e esgotamento sanitário}

De acordo com os relatórios da Joint Monitoring Programme, grupo que monitora o Objetivo do Desenvolvimento Sustentável 6, o acesso ao serviço de água potável tratada e segura é classificado por características das fontes de abastecimento atendendo aos critérios: instalações acessíveis, disponibilidade sempre que necessário e água livre de contaminação. A partir daí, a classificação decai, de acordo com os critérios de distância à água potável e da segurança e qualidade dos poços (WHO; Unicef, 2017). Consideram-se também as fontes aprimoradas, tais como: água encanada, poços tubulares, poços escavados protegidos, fontes protegidas ou ainda águas empacotadas ou entregues (caminhões pipa) (WHO; Unicef, 2017; 2019). Estima-se que uma em cada dez pessoas ainda não tenha acesso à água potável segura, no mundo. Da população rural, a estimativa de pessoas afetadas pela deficiência no acesso à água potável segura é de oito em cada dez habitantes (Opas Brasil, 2019). 
A estimativa de cobertura de água potável tratada e segura, por região do planeta, foi realizada onde os dados disponíveis representavam pelo menos $30 \%$ da população total, e apontou que a África Subsaariana tem proporção mais crítica, com $24 \%$ de cobertura. Em seguida, Ásia Central e Sudeste da Ásia, com 58\%; América Latina e Caribe, 65\%; América do Norte e Europa, 95\%. As demais regiões - Oceania, Sudeste, Oeste e Leste Asiático, Norte da África, Austrália e Nova Zelândia - não apresentaram dados suficientes para estimativas (WHO; Unicef, 2017).

Quanto aos índices de esgotamento sanitário, considerando-se sistemas que separam os excrementos do contato humano de forma independente para cada residência, as classes de saneamento seguro variam de acordo com: complexidade do sistema quanto a tratamento e locais de descarte; armazenamento temporário no local e posterior transporte para outros locais ou transportado através de um esgoto com águas residuais e depois tratado longe da origem (WHO; Unicef, 2017). Nos casos mais precários, em que há inclusive compartilhamento com outras residências, o esgotamento é classificado como limitado, não aprimorado ou ainda, consideram-se as comunidades onde ainda se pratica a defecação a céu aberto. O relatório chama atenção para a definição de sistemas aprimorados: descargas em sistemas de esgoto, fossas sépticas ou latrinas de fossas, banheiros de compostagem ou latrinas de poço com laje (WHO; Unicef, 2017).

Quanto à utilização de serviços de saneamento, duas em cada cinco pessoas no mundo usaram serviços de saneamento seguro (39\%), no ano de 2015. A estimativa mostra que as demais pessoas utilizam meios pouco desenvolvidos (12\%), defecação a céu aberto (12\%), meios limitados (8\%) ou básicos (29\%) (WHO; Unicef, 2017). A pior das situações quanto a higiene, transmissão de doenças e violência quanto a mulheres e crianças é a defecação a céu aberto, que atinge 892 milhões de pessoas, no mundo (WHO; Unicef, 2017).

A estimativa de cobertura do serviço de saneamento seguro por região do planeta apontou que o pior índice entre as regiões que apresentaram dados foi da América Latina e Caribe, com 23\% de cobertura. Em seguida, o grupo Ásia ocidental e Norte da África, 34\%; Leste e Sudeste Asiático, 55\%; Austrália e Nova Zelândia, 68\% e América do Norte e Europa, com 78\% de cobertura de esgotamento sanitário (WHO; Unicef, 2017).

\section{Contextualização socioambiental do acesso ao saneamento básico no Brasil}

Observada a precariedade de esgotamento sanitário seguro na América Latina e Caribe, discute-se o saneamento básico no Brasil. ${ }^{1}$

A Lei Federal n.9.443/1997 estabelece diretrizes para a gestão dos múltiplos usos da água. A diretriz normativa que regulamenta o serviço de abastecimento de água por rede pública, principal forma de acesso, é a Lei Federal n.11.445/2007, que estabelece as diretrizes nacionais para o saneamento bási- 
co, considerando: abastecimento de água potável, esgotamento sanitário, limpeza urbana e manejo de resíduos sólidos e drenagem e manejo de águas pluviais urbanas, e traz como primeiro princípio fundamental a universalização do acesso (Art. $3^{\circ}$, Lei Federal n.11.445/2007).

Antes de 2007, o Brasil tinha um vazio institucional no setor de saneamento, gerador de passivo na definição de políticas públicas para os serviços de abastecimento de água, esgotamento sanitário, manejo dos resíduos sólidos e drenagem de águas pluviais (Borja, 2014). Tal passivo resultou na deficiência do atendimento desses serviços, especialmente "em áreas periurbanas e rurais, onde residem as populações mais pobres" (Murtha et al., 2015, p.193), caracterizando um cenário de desigualdade socioambiental (Fracalanza et al., 2013; Britto, 2010; Maricato, 2003).

A fase que antecede a atual política federal do setor foi caracterizada pela centralização das ações na União através do Plano Nacional de Saneamento (Planasa), elaborado no período de ditadura civil-militar, anos 1970, ampliando serviços de abastecimento de água e de esgotamento sanitário (Costa; Ribeiro, 2013; Jacobi et al., 2009). Por outro lado, o Planasa privilegiou as regiões do sul e do sudeste brasileiros, com maiores investimentos nas cidades mais populosas e nas camadas de maior renda (Costa; Ribeiro, 2013). Investiu-se prioritariamente em abastecimento de água e menos em esgotamento sanitário. Essa precariedade dos sistemas de coleta e tratamento de esgotos resultou nos índices de desigualdade atuais.

A Lei Federal n.11.445/2007 trouxe instrumentos que rompem com o modelo do Planasa e representou uma nova política para o setor (Costa; Ribeiro, 2013). Foi inaugurada "uma nova fase na gestão dos serviços públicos de saneamento básico no país" (Borja, 2014, p.443), com a proposição de abordagem integrada do setor do saneamento básico com outros setores, como de recursos hídricos; e com a ampliação da comunidade de pares na gestão dos serviços públicos de saneamento básico (Paz, 2015). Ainda assim, há dificuldades no avanço para o enfrentamento dos déficits de acesso aos serviços, pois a permanência da ação "de grupos econômicos e políticos na definição da ação estatal revelou as dificuldades de se avançar para um projeto mais democrático, universalista e inclusivo" (Borja, 2014, p.443).

Em 2010, o Brasil tinha uma população de 190,8 milhões de habitantes (IBGE, 2011), estimada para 2019 em 210,1 milhões de habitantes (IBGE, 2019). É o país mais urbanizado da América Latina, com $86 \%$ da população vivendo em áreas urbanas (Cepal, 2014). Os indicadores oficiais apresentam que $92 \%$ das pessoas são atendidas por abastecimento de água e $81 \%$ por esgotamento sanitário (WHO; Unicef, 2014). Porém, persiste uma desigualdade significativa entre as áreas urbana e rural: enquanto $97 \%$ da população urbana tem acesso a água potável, $67 \%$ da população rural tem acesso a este serviço; o acesso ao afastamento dos esgotos é 87\% nas áreas urbanas e 49\% nas áreas rurais (WHO; 
Unicef, 2014). A disparidade ocorre também por classes de renda familiar: em 2012 , somente $67,5 \%$ da população extremamente pobre tinha acesso à rede de água (Ipea, 2014).

Após a conclusão do período estabelecido para os Objetivos de Desenvolvimento do Milênio (ODM) 2000-2015, e da transição para o programa Objetivos do Desenvolvimento Sustentável (ODS), que abrange o período de 2015 a 2030, no Brasil, o Grupo de Trabalho da Sociedade Civil para a Agenda 2030 do Desenvolvimento Sustentável (GT Agenda 2030), formado por ONG, movimentos sociais, fóruns e fundações brasileiras, reunidos desde as negociações da Agenda 2030, monitora a implementação dos ODS e elabora relatórios que apresentam análises deste trabalho. O Relatório Luz 2019 (GT Agenda 2030, 2019) considera que a situação é alarmante para abastecimento de água, coleta e tratamento de esgoto, baseados nos dados do Sistema Nacional de Informações sobre Saneamento (SNIS) para o ano de 2017. Mais de 40 milhões de brasileiros não têm acesso à água potável e mais de 100 milhões não têm o esgoto coletado. O Relatório aponta também que locais com os piores índices são os mesmos que apresentam alta vulnerabilidade socioeconômica.

O não acesso aos serviços de saneamento básico afeta de forma mais intensa a saúde de crianças (Magalhães et al., 2013; Paz et al., 2012; Andreazzi et al., 2007). Estudo da Unicef (2018) revelou que 61\% de crianças e adolescentes no Brasil vivem em cenários de pobreza e são privados de pelo menos um direito dentre: educação, informação, proteção contra o trabalho infantil, moradia, água e saneamento. O que falta para maior número de crianças é o saneamento, seguido por educação e água (Unicef, 2018). Ao mesmo tempo, o país vem experimentando, pela primeira vez em 26 anos, um aumento de óbitos na infância, entre 2015 e 2016 , com um acréscimo em 4,19\% na taxa de mortalidade infantil e em $11 \%$ da mortalidade na infância, relacionadas às condições socioeconômicas do país, especialmente em municípios mais pobres (Rasella et al., 2018).

Por outro lado, em período anterior, o Brasil havia atingido o ODM 7 , conforme estabelecido pela $\mathrm{ONU}$, com foco na redução pela metade da proporção da população sem acesso permanente à água potável e ao esgotamento sanitário, embora haja discrepância entre o acesso entre as populações de baixa e alta rendas. Em 1990, apenas 32,6\% contavam com o abastecimento de água, e em 2012 passou a ser $67,5 \%$ (Ipea, 2014). Para o esgotamento sanitário, são medidas aceitáveis a rede geral de coleta e a fossa séptica. A redução da população sem acesso a estes sistemas caiu de 47\% em 1990 para 23\% em 2012, menos da metade tendo então alcançado a meta (Ipea, 2014). A $4^{\text {a }}$ meta do ODM 7 , que trata de habitantes vivendo em assentamentos precários, também fora alcançada para aquele período, com um aumento de mais de 100 milhões de habitantes vivendo em melhores condições (Ipea, 2014). Em áreas urbanas, a redução de habitantes vivendo em condições precárias foi de 53,5\% em 1990 para 36,6\% em 2012 (Ipea, 2014). 
Embora os indicadores de cobertura de abastecimento de água sejam relativamente satisfatórios, pois demonstram ampliação das redes, existem questionamentos sobre as referências (Galvão Junior, 2009; SNSA, 2013). Os indicadores oficiais de saneamento, como os produzidos pelo SNIS para o acesso às redes de abastecimento e de coleta de esgotos, não indicam se os princípios da Lei Federal n.11.445/2007 - acesso universal, equidade, integridade e sustentabilidade - estão sendo cumpridos na prestação dos serviços (Aleixo et al. 2016), pois não representam necessariamente o acesso a um serviço de qualidade, já que a avaliação apenas identifica o domićlio coberto pela rede e não aborda a questão da qualidade do abastecimento (Aleixo et al. 2016; Galvão Junior, 2009).

No sentido de se trabalhar melhor os indicadores de atendimento dos Serviços de Água e Esgotos (SAE) e do manejo de resíduos sólidos, o Plansab, aprovado em dezembro de 2013, trabalha com o conceito de déficit de saneamento com a população não atendida por serviços públicos ou individuais; ou com atendimento precário (SNSA, 2013). Essa proposta foi incorporada também pelo Programa Nacional de Saneamento Rural (Brasil, 2019), processo iniciado em 2010, que culminou no lançamento do Programa, Portaria do Ministério da Saúde n.3.174/2019.

Seguindo essa definição, em 2010 a população com atendimento adequado aos serviços de saneamento básico era menor que o número apresentado pelos dados oficiais do SNIS e da Pesquisa de Saneamento Básico do IBGE. Os dados oficiais indicavam o acesso ao abastecimento de água e ao esgotamento sanitário por, respectivamente, $85,8 \%$ e $53 \%$ da população brasileira (IBGE, 201 l; SNSA, 2013). Porém, se fosse considerado o atendimento adequado a esses serviços, como a oferta de água potável sem intermitência e a coleta dos esgotos seguida de tratamento ou o uso de fossa séptica, os índices passariam a representar $59,4 \%$ da população com acesso a água e 39,7\% com esgotamento adequado (SNSA, 2013)

Por fim, destacam-se como maiores desafios brasileiros no setor do saneamento o atendimento nas áreas rurais e as urbanas de vulnerabilidade socioambiental e o tratamento do esgotamento sanitário, tanto em relação ao percentual tratado, como ao nível do tratamento. Acrescenta-se, ainda, a necessidade de se considerar a exclusão social no acesso à água, e a discussão em pauta sobre a água e o esgotamento sanitário como direitos humanos.

\section{O acesso à água e ao esgotamento sanitário como direito humano}

O acesso à água potável e ao esgotamento sanitário são essenciais para saúde e qualidade de vida (Heller, 2015; Paz et al., 2012) e são reconhecidos como direito humano (UN, 2010). Pela Constituição Federal de 1988, a saúde é garantida como direito social (Art. 196) e o meio ambiente equilibrado como direito de todos (Art. 225). No entanto, existem divergências nos indicadores de acesso aos serviços de saneamento básico utilizados como referência para os investimentos e assimetrias na forma como a universalização é encontrada em documentos que norteiam o setor do saneamento básico no Brasil. 


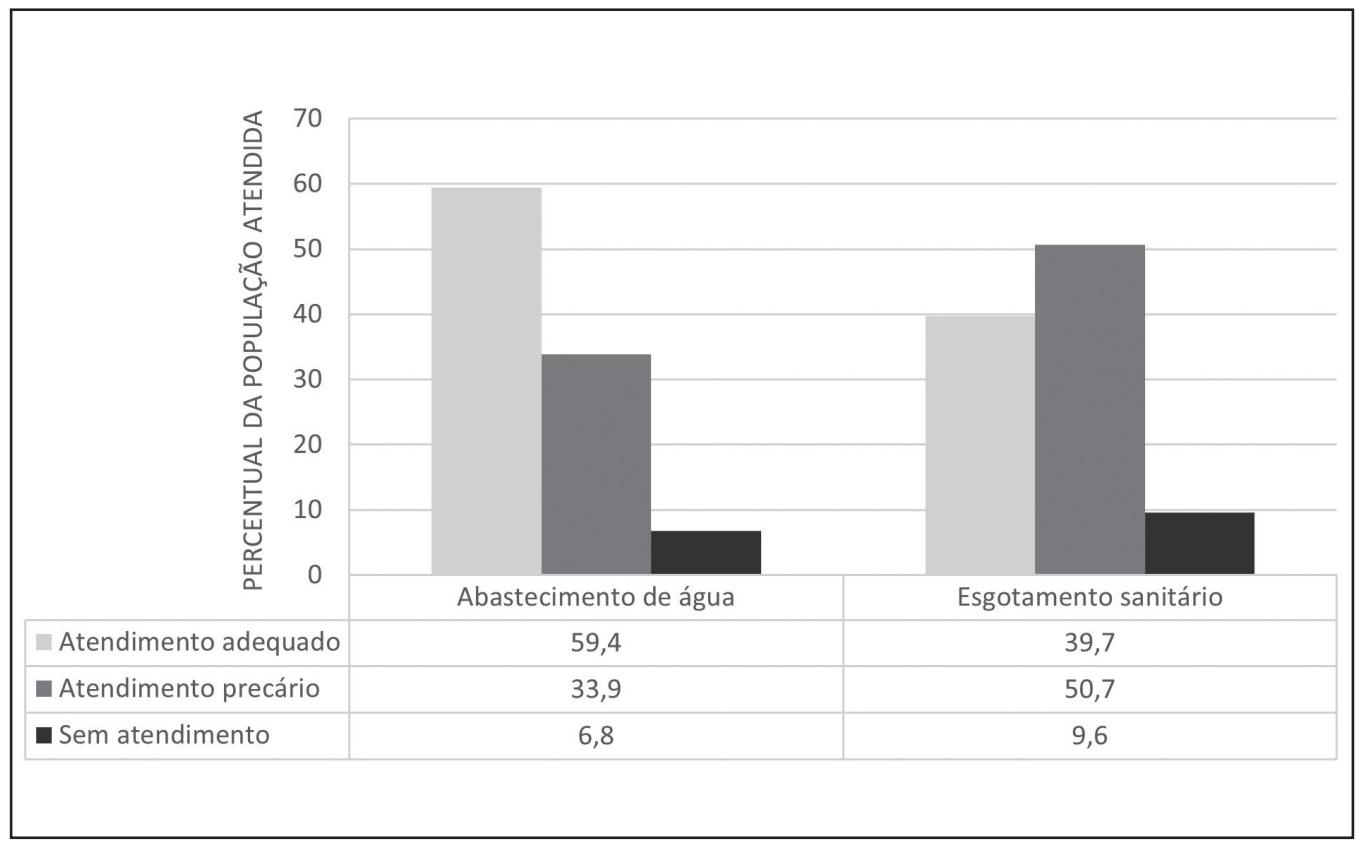

Fonte: SNSA (2013).

Figura 1 - Porcentagem de atendimento aos serviços de abastecimento de água, esgotamento sanitário e manejo de resíduos sólidos em 2010 (Brasil).

Comumente os índices de atendimento à água e ao esgotamento sanitário referem-se à população urbana, como exposto anteriormente. Mas a população das áreas centrais urbanas não representa a totalidade da população que deve ter acesso aos serviços de saneamento, considerando os princípios da equidade (Heller, 2015) e da água como um bem comum (Hess; Ostrom, 2007), desconsiderando, em grande parte, as populações rural e periférica, que geralmente são as que mais necessitam dos serviços de infraestrutura sanitária (Aleixo et al., 2016; Murtha et al., 2015; Fracalanza et al., 2013; Britto, 2010).

Por outro lado, não há consenso sobre a utilização do termo "direitos humanos" quando se discute universalização do acesso a água e ao esgotamento sanitário em quantidade e qualidade. Segundo Bakker (2007), em muitos países, direitos humanos são compatíveis com provisão de água pelo setor privado e muitas companhias privadas têm adotado o discurso do direito humano à água para provê-la enquanto mercadoria e entrar no Mercado da Água.

A alternativa ao uso da expressão água e esgotamento sanitário enquanto direitos humanos tem sido adotada por autores como Dardot e Laval (2014) com os comuns, ou commons. A ideia dos commons seria sair da ideia de que todos têm direito à água, mas de fato, ninguém se responsabiliza por fornecê-la. Além disso, quando a água é considerada um bem econômico, sua racionalização está associada a seu preço, e quanto mais escassa, mais se está disposto a pagar por ela. Isso de fato exclui populações vulneráveis de seu uso e, apesar de 
ser um direito humano, a noção de bem comum deixa a água associada a usos ecossistêmicos e contrapõe, segundo Bakker (2007), a água enquanto mercadoria, em uma estratégia mais efetiva no combate a sua privatização. Ao considerar a água como um bem comum, os investimentos em água e saneamento, considerando as tecnologias apropriadas para cada cenário e as peculiaridades locais e regionais, superariam as centralidades territoriais, sociais e econômicas. A democratização do acesso à água e ao saneamento: "is guided by the idea that improvements in service access conditions should take place primarily among the socially excluded groups, thereby contributing towards a reduction in inequality" (Aleixo et al., 2016, p.64).

Os autores enfatizam ainda a relevância de se considerar os elementos das iniquidades na provisão dos serviços do contexto macro - demográficos, socioeconômicos, políticos e culturais - que se refletem nas características microtextuais (Aleixo et al., 2016). Em um momento em que as desigualdades no acesso à água crescem, e que o déficit é maior em grupos de maior vulnerabilidade socioambiental (Aleixo et al., 2016), a busca pela universalização precisa superar tais iniquidades, e estar consonante aos preceitos da justiça ambiental. Nessa óptica, para se equalizar tais disparidades, parte-se do pressuposto que os esforços no acesso à água e ao saneamento são necessários para a populações dele excluídas para se alcançar a universalização almejada.

\section{Que universalização queremos?}

Alguns esforços nas agendas políticas internacionais e nacional têm sido feitos para trabalhar de forma integrada com os serviços de infraestrutura sanitária e a gestão de recursos hídricos e garantir o acesso à água como um "direito universal". As políticas federal, nacional, Estadual e regional, aqui analisadas, preveem a gestão integrada dos recursos hídricos com a gestão dos serviços públicos de saneamento básico (Paz, 2015). No entanto, quando se lê a "universalização" do acesso aos serviços de saneamento básico, entende-se que o objetivo é promover o acesso aos serviços para toda a população de um território. Procurou-se, portanto, identificar documentos que disciplinam o saneamento básico de modo multinível, a partir de um estudo de caso da região hidrográfica dos rios Sorocaba e Médio Tietê. Na escala Federal, considerou-se a Política Federal de Saneamento Básico (Plansab) - (Lei Federal n.11.445/2007) e o Programa Nacional de Saneamento Rural, inaugurado em 2019. Em escala estadual (São Paulo), a "Política Estadual de Saneamento Básico” (Pesb) e para a escala regional, o "Plano Regional Integrado de Saneamento Básico" (Prisb) da bacia hidrográfica dos rios Sorocaba e Médio Tietê, Unidade de Gerenciamento de Recursos Hídricos 10 do Estado de São Paulo (UGRHI-10).

Entende-se que a definição trazida pela Política Nacional sobre a "ampliação progressiva do acesso de todos os domicílios ocupados ao saneamento básico" considera a totalidade dos municípios, independente da condição do domicílio, seja ela urbana, periurbana ou rural; inclusive as áreas irregulares, se 
consolidadas, deveriam ser contempladas para atender à Resolução da ONU, que declara a água potável e o esgotamento sanitário direito humano essencial, e que o mesmo deve ser contínuo e abranger todos (UN, 2010).

O Plansab considera as áreas rurais em seu discurso e embora não defina diretrizes, dá encaminhamento para o Programa Nacional de Saneamento Rural (PNSR) que foi discutido e construído de forma descentralizada e participativa desde 2010, voltado para o saneamento rural e considerando as diferentes realidades de organização rural no Brasil. Nesse sentido, cabe ressaltar que a lógica de prestação de serviços de saneamento em áreas rurais e urbanas é diferente, tanto nas tecnologias apropriadas como na forma de gestão, sendo necessário um programa voltado para essas localidades.

Apesar de prevista a universalização do saneamento em áreas urbanas consolidadas e em áreas rurais, estas últimas pelo Programa Nacional de Saneamento Rural publicado e endossado pela Portaria do Ministério da Saúde n.3.174/2019, nota-se que a parcela da população que reside em áreas periurbanas não tem sido contemplada nas metas de governo, por estarem, geralmente, em condições fundiárias irregulares (Aleixo et al., 2016; Murtha et al., 2015; Fracalanza et al., 2013; Paz et al., 2012; Britto, 2010; Maricato, 2003).

No sentido de lidar com os déficits de saneamento rural socialmente produzidos, o Programa Nacional de Saneamento Rural está centrado "nos princípios de direitos humanos, na promoção da saúde, na erradicação da pobreza extrema e no desenvolvimento rural solidário e sustentável" (Brasil, 2019, p.36) e estruturado em três eixos estratégicos: Gestão dos Serviços, Educação e Participação Social e Tecnologia (Brasil, 2019). Esse Programa lida, potencialmente, com os desafios do setor, pois considera as medidas estruturais em saneamento rural, com metas de curto, médio e longo prazos, em conjunto com os arranjos institucionais e investimentos necessários para sua operação (Brasil, 2019). Considera, ainda, a valorização histórica do contexto urbano para o setor do saneamento básico, e a ruralidade brasileira com suas diferentes características de arranjos territoriais, considerando, inclusive, os "rurais-urbanos", ou seja, as áreas que, segundo o IBGE, são urbanas, porém, que possuem características mais próximas do rural.

$\mathrm{Na}$ Política Estadual esta questão não é especificada, apenas são considerados os princípios da Lei Federal. Esta postura atribui um papel importante aos planos regionais e municipais na definição das metas estabelecidas para a universalização do setor dos serviços de saneamento básico no estado de São Paulo. Em nível regional, o Prisb da bacia hidrográfica dos rios Sorocaba e do Médio Tietê deixa claro que as diretrizes e metas para os quatro componentes dos serviços de saneamento básico consideram apenas as áreas urbanas, mantendo a cultura das concessionárias de saneamento, que não costumam levar serviços de saneamento para comunidades rurais ou isoladas, salvo exceções.

Este cenário de negligência compactuada do acesso a certas camadas da população corrobora a análise de Castro (2013), sobre as desigualdades sociais 
estruturais e políticas de água e esgotos da corrente dominante serem condicionantes sistêmicos que afetam a universalização desses serviços essenciais. Os fatores e processos sociais em longo prazo influenciam significativamente na moldagem e determinação da organização dos SAE; e embora haja um aumento do reconhecimento de que os principais desafios para os SAE não são técnicos e físico-naturais, mas sociais, corroboram a afirmação do autor sobre as dimensões sociais negligenciadas (ibidem). Castro (2013) traz como exemplo as desigualdades observadas na Bolívia e no Brasil, com condicionantes diferenciadas para grupos especiais da população; onde as desigualdades sociais estruturadas raramente são detectadas nos estatutos sociais das prestadoras dos serviços de saneamento.

Vários autores apontam que o sucesso para a universalização dos SAE em países desenvolvidos foi a estatização da prestação dos serviços até que estes atendessem toda a população; e que os países bem-sucedidos no setor que optaram pela política de privatização dos serviços, o fizeram após a universalização dos SAE (Castro, 2013; Pezon, 2013; Barraqué, 2013; Swyngedouw, 2013; Bakker, 2007). Nesse sentido, Castro (2013) defende que as políticas dominantes para o setor impõem obstáculos na consecução da universalização, espcialmente onde é mais necessária e que as políticas neoliberais, norteadas pelo mercado, foram impostas ao setor ao longo do processo de globalização econômica.

O Congresso Nacional discute, atualmente, novo Marco Regulatório para o saneamento básico, o Projeto de Lei Federal n.4162/19. Uma das críticas que se faz a este PL é que ele afeta o subsídio cruzado que garante o serviço de abastecimento para os municípios pequenos que poderão ter aumento das tarifas caso este ponto não seja revisto. Por não serem lucrativos para as empresas privadas, estes municípios podem ser preteridos no processo de licitação para os serviços de saneamento como está proposto no PL 4162/19. Independentemente das mudanças que possam alterar alguns artigos deste PL, é fato que a relação do Estado brasileiro com a água passa por profundas mudanças no que concerne à transferência do seu controle para o setor privado. Sobre isso, cabe observar que estudos de vários autores mostram as limitações da prestação privada dos serviços de saneamento básico em relação à universalização do acesso à equidade nos investimentos (Castro, 2013; Pezon, 2013; Barraqué, 2013; Swyngedouw, 2013; Britto, 2010; Bakker, 2007).

Quanto aos indicadores considerados para dimensionar a universalização, o plano de saneamento da UGRHI-10 apresenta indicadores quantitativos para o abastecimento de água. Em relação ao esgotamento sanitário, aborda-se somente a qualidade do tratamento dos resíduos, mas não a qualidade da cobertura pela rede de infraestrutura. Ressaltamos que, embora se utilize o termo "universalização", as metas destes planos consideram tão somente as áreas urbanas como as áreas de concessão dos serviços pela empresa prestadora dos SAE.

De acordo com análise do GT Agenda 2030 (2019), é recomendado garantir a participação social efetiva nas decisões sobre recursos hídricos e sa- 
neamento, com atenção à inclusão de comunidades em vulnerabilidade social, garantir a transparência da gestão pública dos recursos hídricos e saneamento, incluindo comitês de bacias e empresas com outorgas de serviços, entre outras recomendações.

Para alguns autores, o índice de cobertura não é suficiente para indicar a universalização em termos qualitativos, ou de atendimento adequado, como apresenta o Plansab (SNSA, 2013). Os indicadores de cobertura não consideram a qualidade do serviço e a continuidade do mesmo (Aleixo et al., 2016; Heller, 2015; Galvão Junior, 2009). Portanto, a universalização baseada apenas nos atuais índices de cobertura dos serviços não representa o acesso da população aos SAE em qualidade e contínuo, nos termos da Resolução da ONU (UN, 2010) e dos princípios fundamentais da Lei Federal n.11.445, de 2007, apresentando um contraditório de seu conceito: como pensar numa universalização do acesso à água e ao esgotamento sanitário sem incorporar a população excluída de tais serviços?

\section{Conclusões}

Dentre os múltiplos usos da água, destacamos o consumo humano pelo seu papel na manutenção da vida. Por esse motivo, a integração entre a gestão dos serviços públicos de saneamento básico e da água é prevista nestas duas políticas. Ainda assim, há alto nível de exclusão de seu acesso entre as populações vulneráveis.

Uma parte considerável da população brasileira não tem acesso aos serviços de água e de saneamento de forma segura e não compõe os dados oficiais por estar em regiões rurais ou fora das áreas de concessão das empresas prestadoras destes serviços. O país está distante de um cenário de universalização do acesso a estes serviços, especialmente com relação às populações excluídas dos centros urbanos, dificultando a definição de uma agenda para a universalização de tais serviços. Além disso, os atuais indicadores de acesso aos serviços de forma segura não consideram toda a população brasileira. O Plansab propõe novas formas de se apresentar os índices de acesso; no entanto, tal proposta ainda se apresenta como uma tentativa isolada de aprimoramento dos indicadores de acesso aos serviços de saneamento básico. Existe um contraditório entre o conceito de universalização e os mecanismos existentes para alcançá-la.

A água não tem sido distribuída de forma justa e igualitária para a população brasileira. E esta distribuição desigual está estruturada na gestão, prestação e no sistema de informação sobre os serviços de saneamento básico. Além da abordagem da água e do saneamento como um direito humano, propomos também considerar a água como um common, ou seja, que é de todos, que deve ser disponibilizado a todos, sem iniquidades.

Isto significa incluir as populações de baixa renda, rurais e periurbanas nos cálculos de indicadores de acesso a água e ao esgotamento sanitário, dentre outros, quando isto não ocorre. E, mais que isso, incluir essas populações en- 
quanto prioridades como beneficiários de políticas públicas distributivas dos serviços de água e de esgotamento sanitário, de modo particular, e de saneamento básico, de uma forma ampla, com resíduos sólidos e drenagem.

Nota

1 Artigo elaborado e submetido antes da revisão do marco legal do setor do saneamento básico com a promulgação da Lei n.14.026/2020.

\section{Referências}

ALEIXO, B. et al. Human Right in Perspective: Inequalities in Access to Water in a Rural Community of the Brazilian Northeast. Ambiente e Sociedade, São Paulo, v.19, n.1, p.63-84, jan./mar. 2016.

ALVES, E. M. Trajetória das decisões sobre políticas públicas de esgotamento sanitário e as influências das coalizões de defesa: Estudo de Caso de Ubatuba - SP. São Paulo, 2018. 24lf. Tese (Doutorado em Ciência Ambiental) - Programa de Pós-Graduação em Ciência Ambiental, Instituto de Energia e Ambiente, Universidade de São Paulo.

ANDREAZZI, M.; BARCELOS, C.; HACON S. Velhos indicadores para novos problemas: a relação entre saneamento e saúde. Rev Panamericana de Salud Publica, v.22, n.3, p.211-7, 2007.

BAKKER, K. The "Commons" Versus the "Commodity": Alter-globalization, Anti-privatization and the Human Right to Water in the Global South. Antipode (Online), v.39, p.430-55, 2007. doi: 10.1111/j.1467-8330.2007.00534.x

BARRAQUÉ, B. O desenvolvimento dos serviços na Europa: da diversidade para a convergência? In: HELLER, L.; CASTRO, J. E. (Org.) Politica pública e gestão de serviços de saneamento. Ed. ampl. Belo Horizonte: Editora UFMG; Rio de Janeiro: Editora Fiocruz, 2013. p.313-36.

BORJA, P. C. Política pública de saneamento básico: uma análise da recente experiência brasileira. Saúde Soc. (Online), v.23, n.2, p.432-47, jun. 2014. doi: 10.1590/S010412902014000200007.

BRASIL. Ministério da Saúde. Fundação Nacional de Saúde. Programa Nacional de Saneamento Rural. Brasília: Funasa, 2019.

BRITTO, A. L. Tarifas sociais, justiça social e justiça ambiental no acesso aos serviços de abastecimento de água e esgotamento sanitário no Brasil. In: CONFERÊNCIA INTERNACIONAL WATERLAT: Tensão entre justiça ambiental e justiça social na América Latina: o caso da gestão da água, 2010, São Paulo. Anais... São Paulo: 2010. $15 \mathrm{p}$.

CASTRO, J. E. Políticas públicas de saneamento e condicionantes sistêmicos. In: HELLER, L.; CASTRO, J. E. (Org.) Política pública e gestão de serviços de saneamento. Ed. ampl. Belo Horizonte: Editora UFMG; José Esteban Castro 2013; Rio de Janeiro: Editora Fiocruz, 2013. p.53-75.

CEPAL - COMISIÓN ECONÓMICA PARA AMÉRICA LATINA Y EL CARIBE. 
Anuario Estadístico de América Latina y el Caribe 2013. LC/G.2582-P, Santiago, Chile: CEPAL/Naciones Unidas, 2014.

COSTA, S. S. da; RIBEIRO, W. A. Dos porões à luz do dia: um itinerário dos aspectos jurídico-institucionais do saneamento básico no Brasil. In: HELLER, L.; CASTRO, J. E. (Org.) Política pública e gestão de serviços de saneamento. Ed. ampl. Belo Horizonte: Editora UFMG; José Esteban Castro 2013; Rio de Janeiro: Editora Fiocruz, 2013. p.467-82.

DARDOT, P.; LAVAL, C. Commun: Essai sur la Révolution au XXI Siècle. Paris: La Découverte, 2014. 593p;

FRACALANZA, A. P.; JACOB, A. M.; EÇA, R. F. Justiça ambiental e práticas de governança da água: (re) introduzindo questões de igualdade na agenda. Ambiente $e$ Sociedade, São Paulo, v.16, n.1, mar. 2013.

GALVÃO JUNIOR, A. C. Desafios para a universalização dos serviços de água e esgoto no Brasil. Rev. Panamericana de Salud Publica, v. 25, n.6, p.548-56, 2009.

GRUPO DE TRABALHO DA SOCIEDADE CIVIL PARA AGENDA 2030 (GT Agenda 2030). III Relatório Luz da Sociedade Civil da Agenda 2030 de Desenvolvimento Sustentável - Brasil. 2019. Online. Disponível em: <https://brasilnaagenda2030. files.wordpress.com/2019/09/relatorio_luz_portugues_19_final_v2_download.pdf>.

HELLER, L. The crisis in water supply: how different it can look through the lens of the human right to water? Perspectives. Cad. Saúde Pública, v.31, n.3, mar. 2015. doi: 10.1590/0102-311XPE010315

HESS, C.; OSTROM, E. Understanding Knowledge as a Commons: From theory to practice. Cambridge, Mass: MIT Press, 2007.

IBGE - INSTITUTO BRASILEIRO DE GEOGRAFIA E ESTATÍSTICA. Censo demográfico 2010. Instituto Brasileiro de Geografia e Estatística: Rio de Janeiro, 2011.

Cidades e Estados. Instituto Brasileiro de Geografia e Estatística: Rio de Janeiro, 2019. Disponível em: <https://www.ibge.gov.br/cidades-e-estados. html?view=municipio $>$.

IORIS, A. A. R. O que é justiça ambiental. Ambiente e Sociedade, Campinas, v.12, n.2, p.389-92, jul./dez. 2009.

IPEA - INSTITUTO DE PESQUISA ECONÔMICA APLICADA. Objetivos de desenvolvimento do Milênio: relatório nacional de acompanhamento. Coord. Instituto de Pesquisa Econômica Aplicada e Secretaria de Planejamento e Investimentos Estratégicos; supervisão: Grupo Técnico para o acompanhamento dos ODM. Brasília: Ipea, MP, SPI, 2014.

JACOBI, P. R. et al. Governança da água no Brasil: dinâmica da política nacional e desafios para o futuro. In: JACOBI, P. R.; SINISGALI, P. A. de A. (Org.) Governança da água e políticas públicas na América Latina e Europa. São Paulo: Annablume, 2009. p.49-82.

MAGALHAES, K. A. et al. A habitação como determinante social da saúde: percepções e condições de vida de famílias cadastradas no programa Bolsa Família. Saúde Soc., São Paulo, v.22, n.1, p.57-72, mar. 2013.

MARICATO, E. Metrópole, legislação e desigualdade. Estud. Av., São Paulo, v.17, n.48, p.151-66, maio-ago., 2003. 
MURTHA, N. A.; CASTRO, J. E.; HELLER, L. Uma perspectiva histórica das primeiras políticas públicas de saneamento e recursos hídricos no Brasil. Ambient. Soc., São Paulo, v.18, n.3, p.193-210, sept. 2015.

NAÇÕES UNIDAS BRASIL. PNUD explica transição dos Objetivos do Milênio aos Objetivos de Desenvolvimento Sustentável. Online. Brasil, 08.12.2015. Disponível em: <https://nacoesunidas.org/pnud-explica-transicao-dos-objetivos-do-milenio-aos-objetivos-de-desenvolvimento-sustentavel/>. Acesso em: 26 abr. 2020.

OPAS BRASIL - ORGANIZAÇÃO PAN-AMERICANA DE SAÚDE. Uma em cada três pessoas no mundo não tem acesso à água potável, revela novo relatório do UNICEF e da OMS. Disponível em: <https://www.paho.org/bra/index.php?option=com_ content\&view $=$ article $\& i d=5970$ :uma-em-cada-tres-pessoas-no-mundo-nao-tem-acesso-a-agua-potavel-revela-novo-relatorio-do-unicef-e-da-oms\&Itemid=839>. Acesso em: 18 jun. 2019.

PAZ, M. G. A. Integração das politicas públicas de recursos hídricos e saneamento: a bacia hidrográfica dos rios Sorocaba e Médio Tietê. São Paulo, 2015. Tese (Doutorado em Ciências Ambientais) - Universidade de São Paulo. doi: 10.11606/T.106.2015.tde$17072015-213348$

PAZ, M. G. A. da; ALMEIDA, M. F. de; GUNTHER, W. M. R. Prevalência de diarreia em crianças e condições de saneamento e moradia em áreas periurbanas de Guarulhos, SP. Rev. Bras. Epidemiol. [online], v.15, n.1, p.188-97, 2012. doi: 10.1590/S1415-790X2012000100017.

PEZON, C. A experiência francesa: Descentralização e delegação. In: HELLER, L.; CASTRO, J. E. (Org.) Política pública e gestão de serviços de saneamento. Ed. ampl. Belo Horizonte: Editora UFMG; José Esteban Castro 2013; Rio de Janeiro: Editora Fiocruz, 2013. p.261-79.

RASELLA, D. et al. Child morbidity and mortality associated with alternative policy responses to the economic crisis in Brazil: A nationwide microsimulation study. PLOS Medicine, v.15, n.5, e1002570, 2018. doi: 10.1371/journal.pmed.1002570

SCHMIDT, L.; GOMES, C.; JACOBI, P. R. Saberes interdisciplinares para adaptação: comunidades, academia e meio ambiente. In: TORRES, P. et al. (Org.) Governança e Planejamento Ambiental: adaptação e políticas públicas na Macrometrópole Paulista. Rio de Janeiro: Letra Capital, 2019. p.15-22.

SNIS - SISTEMA NACIONAL DE INFORMAÇÕES SOBRE SANEAMENTO. MCidades - Ministério das Cidades. Glossário de Indicadores - Água e Esgotos. S.d. SNIS, MCidades. Disponível em: <http://snis.gov.br/glossarios> Acesso em: 25 jun. 2018.

- Série Histórica. s. d. Disponível em: <http://www.cidades.gov.br/serieHistorica/\#>. Acesso em: 15 out. 2014.

SNSA - SECRETARIA NACIONAL DE SANEAMENTO AMBIENTAL. Plano Nacional de Saneamento Básico - Plansab. Brasília: Ministério das Cidades, Secretaria Nacional de Saneamento Ambiental, 2013.

SSRH/CSAN - SECRETARIA DE SANEAMENTO E RECURSOS HÍDRICOS DO ESTADO DE SÃO PAULO. ENGECORPS. Plano regional integrado de saneamento básico. São Paulo: SSRH/CSAN, 2011

SWYNGEDOUW, E. Água e revoltas - A economia política dos serviços públicos es- 
senciais. In: HELLER L.; CASTRO, J. E. (Org.) Política pública e gestão de serviços de saneamento. Ed. Ampl. Belo Horizonte: Editora UFMG; José Esteban Castro 2013; Rio de Janeiro: Editora Fiocruz, 2013. p.76-97.

UN - UNITED NATIONS. General Assembly Adopts Resolution Recognizing Access to Clean Water, Sanitation as Human Right, by Recorded Vote of 122 in Favour, None against, 41 Abstentions. Disponível em: <http://www.un.org/press/en/2010/ gal0967.doc.htm>. Acesso em: 14 dez. 2017.

UNITED NATIONS CHILDREN'S FUND (UNICEF). Pobreza na infância e na adolescência. S. 1.: Unicef, 2018. Disponível em: <https://www.unicef.org/brazil/pt/ pobreza_infancia_adolescencia.pdf>. Acesso em: 22 ago. 2018.

WORLD HEALTH ORGANIZATION (WHO); UNITED NATIONS CHILDREN'S FUND (UNICEF). Country files. Brazil. Join Monnitoring Programme (JMP) for Water Supply and Sanitation. World Health Organizazion, UNICEF. Genebra, 2014. Disponível em: <http://www.wssinfo.org/documents/?tx_displaycontroller[type]=country_ files>. Acesso em: 30 jul. 2014.

Progress on drinking water, sanitation and hygiene: 2017 Updates and SDG Baselines. Genebra, 2017. Disponível em: <https://www.who.int/mediacentre/news/ releases $/ 2017 /$ launch-version-report-jmp-water-sanitation-hygiene.pdf $>$. Acesso em: 20 fev. 2020.

. Joint Monitoring Programme - JMP. Progress on Drinking Water, Sanitation and Hygiene - 2000-2017: Special focus on inequalities. Genebra, 2019. Disponível em: <https://www.who.int/water_sanitation_health/publications/jmp-report-2019/ en/>. Acesso em: 20 fev. 2020.

RESUMO - Dentre os múltiplos usos da água, destaca-se o consumo humano pelo seu papel na manutenção da vida. O objetivo do artigo é discutir a universalização do acesso à água e ao esgotamento sanitário como common. Para discutir essa questão central da universalização dos serviços, o artigo desenvolve-se por meio de quatro pontos fundamentais: i) panorama global do acesso à água potável e ao esgotamento sanitário; ii) contextualização socioambiental do saneamento básico no Brasil; iii) o acesso à água e ao saneamento básico como direito humano; e iv) o desdobramento da definição de universalização dos serviços de saneamento básico em três esferas de gestão da água e como a compreensão da universalização proposta contribui para o desenvolvimento do setor no Brasil. Considera-se o contraditório histórico sobre o conceito de universalização e os mecanismos existentes para medir a evolução e para alcançá-la.

PALAVRAS-CHAVE: Água e saneamento, Universalização, Direito humano, Common.

ABSTRACT - Among the multiple uses of water, human consumption stands out for its role in maintaining life. The objective of this article is to discuss the universalization of access to water and sanitation as common. To discuss this central issue of the universalization of services, the article develops four fundamental points: i) global overview of access to drinking water and sewage; ii) socio-environmental context of basic sanitation in Brazil; iii) access to water and basic sanitation as a human right, and iv) the unfolding of the definition of universal basic sanitation services in three spheres of water manage- 
ment, and how the understanding of the proposed universalization contributes to the development of the sector in Brazil. The article analyzes the historical contradictions around the concept of universalization and the existing mechanisms to achieve it and to measure its evolution.

KEYWORDS: Water and sanitation, Universalization, Human right, Common.

Mariana Gutierres Arteiro da Paz é pesquisadora do Instituto Nacional de Pesquisas Espaciais (Inpe); doutora em Ciência Ambiental pelo Instituto de Energia e Ambiente da Universidade de São Paulo (Procam/IEE/USP), pós-doutora pela Escola de Artes, Ciências e Humanidades da USP (EACH/USP), pós-doutora pelo Centro de Ciência do Sistema Terrestre (CCST/INPE). @-pazmga@gmail.com / https://orcid.org/0000-0003-3055-6184.

Ana Paula Fracalanza é professora livre-docente na Escola de Artes, Ciências e Humanidades da USP (EACH), no Programa de Pós-Graduação em Mudança Social e Participação Política da USP (PROMUSPP/USP) e no Programa de Pós-Graduação em Ciência Ambiental do Instituto de Energia e Ambiente da USP (Procam/IEE/USP). @ - fracalan@usp.br / https://orcid.org./0000-0001-9289-0028.

Estela Macedo Alves é arquiteta e urbanista, pós-doutoranda no Instituto de Energia e Ambiente da USP (IEE/USP); doutora em Ciência Ambiental pelo Instituto de Energia e Ambiente da Universidade de São Paulo (Procam/IEE/USP).

@ - alvesestela@usp.br / https://orcid.org/0000-0003-2095-1818.

Flávio José Rocha da Silva é doutor em Ciências Sociais pela Pontifícia Universidade Católica de São Paulo (PUC-SP), pós-doutor pelo Instituto de Energia e Ambiente da USP (Procam/IEE/USP). @- flaviojoserocha@gmail.com / https://orcid.org/0000-0003-0739-3612.

Recebido em 25.5.2020 e aceito em 18.2.2021.

I, III, IV Universidade de São Paulo, Instituto de Energia e Ambiente, São Paulo, Brasil.

II Universidade de São Paulo, Escola de Artes, Ciências e Humanidades, São Paulo, Brasil. 